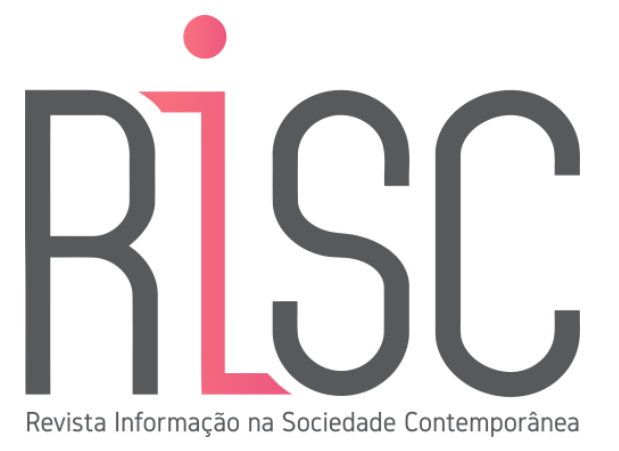

\title{
Práticas mediacionais do projeto Leitura\&Ação na Comunidade Beneficente Zaíla Lavor em Juazeiro do Norte - CE
}

\author{
Arysa Cabral Barros \\ Mestranda do Programa de Pós-Graduação em Biblioteconomia \\ Universidade Federal do Cariri, Juazeiro do Norte, CE, Brasil \\ https://orcid.org/0000-0002-7149-4322 E-mail: arysa.cb@gmail.com
}

Jonathas Luis Carvalho Silva

Pós-doutor em Ciência da Informação (UNESP)

Universidade Federal do Cariri, Juazeiro do Norte, CE, Brasil

(iD) https://orcid.org/0000-0003-3036-0077 E-mail: jonathascarvalhos@yahoo.com.br

Submetido em: 09-01-2021 Reapresentado em: 08-03-2021 Aceito em: 19-05-2021

\section{RESUMO}

Trata sobre as práticas de mediação com vistas a fortalecer as diversas formas de manifestação sociocultural e pedagógica, com base nos impactos viabilizados pelas ações extensionistas do projeto Leitura\&Ação. Denota em seu objetivo geral, investigar as contribuições deste projeto para a Comunidade Beneficente Zaíla Lavor, a partir das práticas mediacionais no âmbito da informação, cultura e educação. Descreve no percurso metodológico a caracterização das técnicas e etapas da pesquisa por meio dos métodos exploratório e descritivo, bem como, a triangulação de estratégias através do estudo de caso. Apresenta o instrumento de coleta de dados (observação participante) e o polo avaliativo (análise qualitativa de conteúdo). Delineia as ações intervencionistas do projeto Leitura\&Ação com o intuito de analisar o impacto das práticas mediacionais na Comunidade Beneficente Zaíla Lavor, a partir da etapa de diagnóstico e das categorias previamente estabelecidas no referencial teórico. Conclui com as discussões finais sobre os resultados alcançados no decorrer das ações extensionistas, constatando-se as novas perspectivas de atuação na Comunidade Beneficente Zaíla Lavor conforme os serviços informacionais desenvolvidos, tendo a mediação da informação como respaldo para galvanizar práticas formativas pelo teor interdisciplinar. 
Palavras-chave: mediação da informação; práticas mediacionais; Comunidade Beneficente Zaíla Lavor; Projeto Leitura\&Ação.

\title{
Mediational practices of the Reading \& Action project in the Zaíla Lavor Charitable Community in Juazeiro do Norte - CE
}

\begin{abstract}
It deals with mediation practices with a view to strengthening the various forms of sociocultural and pedagogical manifestation, based on the impacts made possible by the extension actions of the Leitura\&Ação project. It denotes in its general objective, to investigate the contributions of this project to Comunidade Beneficente Zaila Lavor, based on mediational practices in the field of information, culture, and education. It describes in the methodological path the characterization of the techniques and stages of the research through exploratory and descriptive methods, as well as the triangulation of strategies through the case study. It presents the data collection instrument (participant observation) and the evaluative pole (qualitative content analysis). It outlines the interventional actions of the Leitura\&Ação project to analyze the impact of meditation practices in Comunidade Beneficente Zaíla Lavor, from the diagnostic stage and from the categories previously established in the theoretical framework. It concludes with the final discussions on the results achieved during extension actions, verifying the new perspectives of action in the Comunidade Beneficente Zaíla Lavor according to the informational services developed, having the mediation of information as support to galvanize formative practices by interdisciplinary content.
\end{abstract}

Keywords: mediation of information; mediational practices; Comunidade Beneficente Zaíla Lavor; Project Leitura\&Ação.

\section{INTRODUÇÃO}

Devido aos avanços das Tecnologias da Informação e da Comunicação (TICs), os fenômenos que envolvem a informação vêm transfigurando os aspectos que norteiam o paradigma social do campo da Ciência da Informação $(\mathrm{Cl})$, no que concerne à relação entre o sujeito cognoscente e os aspectos sociais, públicos, econômicos e culturais da informação. Isto posto, percebe-se que estes acontecimentos desenvolveram um quadro de preocupação no campo biblioteconômico a respeito do usuário, da circulação e do acesso à informação.

Nessa perspectiva, a aplicabilidade da mediação da informação nos ambientes informacionais vem a ser uma ação orientadora para as demandas cognitivas e sociais, ao propiciar interferências e intervenções com vista à apropriação da informação, e assim, 
acarretando a construção de conhecimentos, na resolução de problemas e na satisfação das necessidades do usuário. Partindo dessa inferência, fica evidente o papel do bibliotecário mediador como o profissional responsável por facilitar o acesso e uso dessas informações dentro das comunidades inseridas no contexto da Sociedade da Informação, em destaque as comunidades menos assistidas.

O paradigma social da Ciência da Informação propicia um olhar direcionado para as vertentes da informação. A partir desse fenômeno, o sujeito enquadra-se como foco central dos estudos nesse campo, com vistas à construção e reconstrução coletiva de conhecimentos, de maneira dialética e interacionista. Mediante esse paradigma, outras perspectivas de atuação podem alicerçar as práticas biblioteconômicas através de um contexto social, educativo e cultural para propiciar enfoques pragmáticos da mediação informacional no âmbito comunitário.

Em contrapartida, observa-se a escassez dessas práticas mediacionais em ambientes comunitários nos quais existe a indispensabilidade do bibliotecário exercer seu papel enquanto mediador, considerando a abrangência de atuação no campo da Biblioteconomia. Desse modo, trazer um questionamento sobre o campo de atuação biblioteconômico, significa exercer seus postulados, principalmente no que se refere ao setor de serviços de informação em equipamentos culturais, os quais propiciam a dinamização e flexibilização das práticas informacionais nesse sentido.

Por conseguinte, levando em consideração as condições intrínsecas dos centros comunitários como um ambiente holístico na promoção de ações lúdicas direcionadas à construção do conhecimento, bem como a dimensão social que abrange essas práticas mediacionais, elaborou-se o seguinte questionamento: quais as contribuições do projeto Leitura\&Ação para a Comunidade Beneficente Zaíla Lavor, a partir das práticas mediacionais no âmbito da informação, cultura e educação?

A escolha por investigar essa temática justifica-se pela vertente de atuação bibliotecária frente a práticas de mediação informacional nas instituições, visto que esse profissional deve atuar como um agente sociocultural na prestação de serviços de informação de cunho liberal e humanístico, com o intuito de melhor servir à coletividade e suas necessidades informacionais. Isto posto, o bibliotecário, enquanto mediador, 
poderá atuar proativamente englobando três vieses primordiais: conhecimentos, competências e atitudes.

Fundamentado na realidade exposta, a pesquisa tem como objetivo geral: investigar as contribuições do projeto Leitura\&Ação para a Comunidade Beneficente Zaíla Lavor, a partir das práticas mediacionais no âmbito da informação, cultura e educação. Dessa forma, para atingir essa finalidade, traçou-se os seguintes objetivos específicos: a) refletir sobre as perspectivas teórico-conceituais que embasam os estudos relacionados à construção da mediação informacional; b) identificar os elementos que norteiam práticas mediacionais ofertadas pelo projeto Leitura\&Ação na Comunidade Beneficente Zaíla Lavor; c) descrever os impactos mediacionais no que tange às práticas do projeto Leitura\&Ação na Comunidade Beneficente Zaíla Lavor.

\section{CONSIDERAÇÕES TEÓRICO-CONCEITUAIS SOBRE MEDIAÇÃO DA INFORMAÇÃO E SUAS TIPOLOGIAS}

Contemporaneamente, o conceito de mediação vem se consolidando no âmbito do conhecimento científico, devido a sua extensa aplicabilidade como fundamento teórico. No âmbito da Biblioteconomia e Ciência da Informação, a medição se envidou pelo termo informação, uma vez que esse campo do conhecimento se respalda no estudo epistemológico da mediação.

Nesse âmbito, as concepções da mediação se estabelecem a partir do desenvolvimento dos campos, inicialmente da Biblioteconomia e, posteriormente, da Ciência da Informação, no que concerne os equipamentos informacionais inseridos na Sociedade da Informação e a responsabilidade social de propiciar o acesso e uso dessa dimensão aos sujeitos da informação. Mediante o exposto, pretende-se, a seguir, discorrer sobre os pressupostos histórico-conceituais da mediação da informação, assim como os aspectos que determinam sua aplicabilidade em ambientes informacionais, com intuito de fortalecer suas respectivas práticas.

Conforme a bibliografia da área, a mediação da informação começou a ser discutida pela literatura especializada brasileira em Ciência da Informação no final do séc. XX para o início do séc. XXI, pautada nas áreas de Filosofia e Sociologia. O primeiro autor 
a consolidar o termo foi o bibliotecário Oswaldo Francisco de Almeida Júnior, ao retratar mediação da informação como "toda ação de interferência [...] direta ou indireta; consciente ou inconsciente; singular ou plural; individual ou coletiva; que propicia a apropriação de informação que satisfaça, plena ou parcialmente, uma necessidade informacional" (ALMEIDA JÚNIOR, 2008, p. 3). Ao aperfeiçoar seus estudos (ALMEIDA JÚNIOR, 2015), o autor reformula o conceito com o intuito de atender a uma nova perspectiva sobre a mediação da informação, apontando que o processo mediacional deve também gerar conflitos e novas necessidades informacionais para os usuários.

Desse modo, entende-se que todo conceito deve ser analisado em sua integralidade, em razão de cada micro conceito estar intrinsicamente concatenado ao macro. Isto é, a mediação da informação não está apenas ligada à apropriação da informação, mas, sim, à resolução de problemas, satisfação de necessidades, competências do usuário, construção do conhecimento, entre outros micro conceitos, que são alcançados através das interferências propiciadas pelos profissionais da informação.

À vista disso, Silva (2015) complementa a definição supracitada expondo que a mediação da informação pode ser afirmada em três palavras: construção, intervenção e interferência. Neste sentido, o processo de mediação é construído socialmente, tanto pelas ações implícitas e explícitas, quanto pelo incentivo ao posicionamento crítico do usuário, resultando, assim, em relações sociais construídas por intermédio de intervenções e interferências promovidas pela prática mediacional, devido à mediação não residir apenas no ato, mas no impacto que este causa no indivíduo. Com tais características, o autor conceitua mediação da informação como:

[...] um conjunto de práticas construtivas de intervenções e interferências regidas por intencionalidades, normas/regras, correntes teórico-ideológicas e crenças concebidas pelo profissional da informação em interação com os usuários no âmbito de suas realidades cotidianas e experienciais, indicando procedimentos singulares, coletivos e/ou plurais de acesso e uso da informação, estimulando à apreensão e apropriação para satisfação de necessidades de informação (SILVA, 2015, p. 103). 
No que diz respeito às perceptivas teórico-conceituais sobre a mediação da informação, é nítido que Silva apresenta uma certa complementariedade ao conceito pioneiro de Almeida Júnior. Ao passo que Silva (2015) estabelece uma ampliação dessa definição, delineando não apenas a prática intervencionista com finalidade de apropriação da informação, mas a interferência como caráter de transformação social e cognitiva, concebida a partir da intervenção, promovendo reconstruções de conhecimentos pelo usuário e uma reavaliação das práticas mediacionais realizadas pelo profissional da informação. Além disso, para suplementar as informações apresentadas, destaca-se aqui outras concepções teóricas de autores sobre mediação da informação:

a) perspectiva dos sentidos: no processo de construção de sentidos, na qual ocorre a comunicação dos conhecimentos estabelecidos, a mediação da informação atua no movimento de acesso, constituído de ações de comunicação e de transferência/transmissão de informações dispostas nos acervos informacionais. Isto é, a mediação articula na interseção entre a informação, a comunicação e a educação, com o objetivo de estabelecer estratégias a partir das quais se torna possível a construção de saberes e sentidos (GOMES, 2008);

b) perspectiva cognitiva: na prática intervencionista, faz-se necessário compreender e delinear a trajetória lógica do usuário no processo de busca da informação e da construção dos meandros da cognição na apreensão do conhecimento. Dessa forma, a mediação da informação permiti uma harmonia de objetivos entre o que o usuário busca e o que o mediador oferece (VARELA, 2008);

c) perspectiva documental: nesse viés, a mediação da informação, trata-se de uma posição intermediária, um vínculo, entre os pares/comunidade externa e o mundo da pesquisa. O suporte gerado pela mediação é mútuo e flutuante, dependendo diretamente da força das redes construídas e dos atores envolvidos no processo mediacional especializado. A finalidade dessa prática intervencionista é gerar a comunicação científica a partir de estudos documentais para lançar um olhar crítico sobre a sua utilização como material de pesquisa (COUZINET, 2009);

d) perspectiva cultural: a mediação da informação envolve os aspectos relacionados ao acesso/divulgação-circulação da informação, bem como os processos de acesso/apropriação-formação de competências técnico-culturais. No âmbito 
cultural, a mediação viabiliza a disseminação da informação a fim de torná-la pública, especialmente a informação cultural, além do que, busca capacitar e formar os atores envolvidos (individuais e coletivos), através de cursos, oficinas, seminários, projetos abertos etc. (ALMEIDA; DAMIAN, 2015).

Nesse contexto, as discussões no cerne da mediação da informação no campo da $\mathrm{Cl}$ permitem aferir que os autores referidos denotam conceitos que determinam uma visão epistemológica efetiva dessa dimensão. Em contrapartida, é nítido que a mediação da informação, demanda um aprofundamento conceitual, uma vez que existe uma apropriação acrítica pelos pesquisadores da área do conceito em tela, os quais apenas uma adequam o conceito aos problemas e aos casos específicos do campo de estudo (SILVA, 2010).

A partir dessa assertiva, compreende-se a mediação da informação como um fenômeno relacional cíclico das práticas desenvolvidos nas unidades de informação, visto que está inclusa, implícita e/ou explicitamente, nos serviços disponibilizados por esses ambientes, no que diz respeito ao serviço de referência; Serviço de Informação Utilitária (SIU); Disseminação Seletiva da Informação (DSI), serviços técnicos de organização informacional (ex.: classificação, catalogação, indexação, etc.), assim como nas vivências educacionais e culturais. Isto posto, com o intuito de esclarecer essa conceção dimensional que norteia a mediação da informação na $\mathrm{Cl}$, no quadro abaixo será apresentado as diferentes tipologias desse conceito.

Quadro 1 - Tipos de mediação da informação

\begin{tabular}{|c|c|l|}
\hline Autor(a)/Ano & Tipologias & \multicolumn{1}{c|}{ Definições } \\
\hline $\begin{array}{c}\text { Oswaldo } \\
\begin{array}{c}\text { Almeida Júnior } \\
\mathbf{2 0 0 8}\end{array}\end{array}$ & $\begin{array}{c}\text { Mediação } \\
\text { implícita }\end{array}$ & $\begin{array}{l}\text { Ocorre nos espaços dos equipamentos informacionais em que as } \\
\text { ações são desenvolvidas sem a presença física e imediata dos usuários } \\
\text { (ex.: processamento técnico). }\end{array}$ \\
\cline { 2 - 3 } & $\begin{array}{c}\text { Mediação } \\
\text { explícita }\end{array}$ & $\begin{array}{l}\text { Ocorre nos espaços em que a presença do usuário é inevitável, é } \\
\text { condição sine qua non para sua existência, mesmo que tal presença } \\
\text { não seja física, como, por exemplo, nos acessos à distância em que } \\
\text { não é solicitada a interferência concreta e presencial do profissional da } \\
\text { informação. }\end{array}$ \\
\hline $\begin{array}{c}\text { Armando } \\
\text { Malheiro da Silva } \\
\mathbf{2 0 1 0}\end{array}$ & $\begin{array}{l}\text { Associa-se ao paradigma custodial, patrimonialista e historicista } \\
\text { originário, em que a mediação possui uma concepção passiva e até } \\
\text { "negativa", uma vez que a prioridade está na guarda do património } \\
\text { cultural incorporado e acumulado, não no acesso ou na difusão plena } \\
\text { da informação }\end{array}$ \\
\hline
\end{tabular}




\begin{tabular}{|c|c|c|}
\hline & $\begin{array}{l}\text { Pós-custodial/ } \\
\text { informacional }\end{array}$ & $\begin{array}{l}\text { Configura-se como uma multi-mediação, ou seja, nessa tipologia de } \\
\text { mediação prevalece a pluralidade de articulações e de interações } \\
\text { centradas na coleta/ produção, organização e promoção do acesso à } \\
\text { informação. Ela subdivide-se em: institucional; distribuída e/ou } \\
\text { partilhada; e cumulativa. }\end{array}$ \\
\hline \multirow{4}{*}{$\begin{array}{c}\text { Henriette } \\
\text { Ferreira Gomes } \\
2014\end{array}$} & $\begin{array}{l}\text { Caráter } \\
\text { dialógico }\end{array}$ & $\begin{array}{l}\text { O processo mediacional dialógico possibilita a interlocutores distintos } \\
\text { o encontro e a manifestação das subjetividades que emanam da } \\
\text { interlocução inter e intrasubjetiva. Na mediação consciente, a dialogia } \\
\text { torna exequível o exercício da crítica e a observação mais clara das } \\
\text { incompletudes e lacunas que promovem a desestabilização dos } \\
\text { conhecimentos estabilizados em cada sujeito. }\end{array}$ \\
\hline & $\begin{array}{l}\text { Caráter } \\
\text { estético }\end{array}$ & $\begin{array}{l}\text { A dimensão estética, por se tratar de uma ação ligada ao movimento e } \\
\text { geradora de experiências a partir do encontro com a informação e } \\
\text { com os sujeitos que a produzem, promove e disponibiliza o acesso e o } \\
\text { uso da informação. Isto se dá, a partir da efetividade da ação } \\
\text { mediadora, traduzindo uma estética que também pode estar } \\
\text { associada à estética dos próprios ambientes, do discurso e abordagens } \\
\text { do mediador e dos instrumentos, produtos e serviços acessados nesse } \\
\text { ambiente. }\end{array}$ \\
\hline & $\begin{array}{l}\text { Caráter } \\
\text { formativo }\end{array}$ & $\begin{array}{l}\text { Está ligado ao fazer, ao movimento, à ação, cuja operacionalização se } \\
\text { dá através de um ato realizador de algo que, em certa medida acaba } \\
\text { por inventar ou reinventar a ação e o sujeito da ação. Por outra } \\
\text { perspectiva também se observa que toda ação é motivada por } \\
\text { experiências e só é concretizada na experiência. Desse modo, a } \\
\text { experiência (o movimento inerente ao protagonismo) é condição } \\
\text { imprescindível à mediação e à formação. }\end{array}$ \\
\hline & Caráter ético & $\begin{array}{l}\text { Se revela com maior intensidade quando se constata a sua ligação com } \\
\text { o movimento e a vida dos sujeitos que necessitam de informação e } \\
\text { precisam sentir-se acolhidos para desenvolver um sentimento de } \\
\text { pertença ao ambiente informacional. Dessa forma, busca desenvolver } \\
\text { consciência e competência para uma interferência sem manipulações, } \\
\text { garantindo o acolhimento, a escuta, a observação e o diálogo com os } \\
\text { envolvidos na ação, como também o direito de acesso a diversidade } \\
\text { de ideias e o livre pensar, inibindo a censura e o tratamento desigual. }\end{array}$ \\
\hline \multirow{3}{*}{$\begin{array}{l}\text { Jonathas Luiz } \\
\text { Carvalho Silva } \\
2015\end{array}$} & $\begin{array}{l}\text { Mediação } \\
\text { técnica }\end{array}$ & $\begin{array}{l}\text { Concerne as ações de organização, representação da informação } \\
\text { envidadas pelo profissional da informação estimulando o uso da } \\
\text { informação, seja em ambiente físico ou virtual. Por exemplo, a } \\
\text { elaboração de catálogos, interação por e-mail e/ou redes sociais do } \\
\text { acervo do centro de informação, entre outros. }\end{array}$ \\
\hline & $\begin{array}{c}\text { Mediação } \\
\text { pedagógica }\end{array}$ & $\begin{array}{l}\text { Consiste na condução dos procedimentos e heurísticas a serem } \\
\text { utilizadas no processo de mediação. Para tanto, é fundamental um } \\
\text { olhar constante nos estudos de usuários contemplando questões } \\
\text { relativas ao uso do acervo, das condições tecnológicas, do serviço, das } \\
\text { questões de pessoal e avaliação da atuação do centro de informação } \\
\text { de forma geral buscando uma aproximação com a comunidade, assim } \\
\text { como promovendo autonomia para que o usuário tenha condições de } \\
\text { escolha para apreensão e apropriação da informação. }\end{array}$ \\
\hline & $\begin{array}{c}\text { Mediação } \\
\text { institucional }\end{array}$ & $\begin{array}{l}\text { Está relacionada aos procedimentos de como o profissional da } \\
\text { informação irá buscar recursos (financeiros, pessoais, equipamentos, } \\
\text { acervo, instrumentos tecnológicos etc.), seja dentro ou fora da } \\
\text { instituição que o centro de informação está inserido para concretizar } \\
\text { suas ações e interferências, assim como promover sua } \\
\text { sustentabilidade. }\end{array}$ \\
\hline
\end{tabular}

Fonte: Adaptado de Almeida Júnior (2008), Silva (2010), Gomes (2014) e Silva (2015). 
Após as informações ilustradas, percebe-se que a mediação da informação possui um conjunto de dimensões e potencialidades para o desenvolvimento técnico-científico, pedagógico e de aplicação profissional. Estas dimensões e potencialidades possuem relações interdependentes entre si, caracterizando o olhar de cada pesquisador.

Em suma, infere-se que o processo de mediação da informação tem como atorchave o ser humano, caracterizando-se por ser um movimento subjetivo e dinâmico capaz de proporcionar um encontro interacionista entre geradores e receptores da informação, fundamentado nos seus conhecimentos explícitos e tácitos, ao buscar meios para impactar esses indivíduos e suas bases de conhecimentos às demais fontes de informação disseminadas na sociedade (ALMEIDA JÚNIOR, 2008). Nessa conjuntura, o mediador tem a capacidade de facilitar a comunicação e atuar como um terceiro imparcial, com a finalidade de restabelecer o diálogo entre as partes, em busca de uma solução que satisfaça a necessidade dos indivíduos (MARTINS, et al., 2014).

Sabendo disso, um potencial mediador é justamente o bibliotecário, pois a mediação da informação consiste na capacidade de apropriação a partir da construção das relações humanas no âmbito das práticas informacionais. A partir disso, vale frisar a competência desse profissional em relação ao processo de avaliação e análise das necessidades dos usuários, com o intuito de fornecer serviços especializados baseados em suas particularidades, proporcionando o acesso à informação, cultura e educação por meio de práticas sociais, a partir dos múltiplos elementos que norteiam o processo mediacional, dentre estes:

a) mediação da informação no viés do estudo de usuários: por trás do conceito de mediação informacional está a satisfação das necessidades informacionais dos indivíduos, posto que, para suceder o processo mediacional, faz-se necessária a realização de estudos sistemáticos e cientificamente fundamentados, para oferecer um serviço centrado no usuário. O mediador deve introjetar essa capacidade de observar e analisar as necessidades demandas, por isso, os estudos de usuários, configuram-se como um excelente instrumento de trabalho para os mediadores da informação (DUARTE, 2011);

b) mediação da informação no viés da satisfação das necessidades informacionais: uma necessidade de informação deve ser pensada com base nos contextos da 
satisfação. A construção de sentidos situa-se no âmbito da satisfação das necessidades de informação dos usuários, ao promover possibilidades de autonomia da informação, estimulando o diálogo e a construção de informação. Diante disso, a mediação se constitui em um conjunto de práticas alicerçadas no paradigma sociocognitivo e interacionista, pensando o usuário a partir de uma autonomia no processo de construção de sentido, assim como estimula-o a conceber apropriação de informação, visando a satisfação de suas necessidades (SILVA, 2012);

c) mediação da informação no viés da formação de competências: a mediação da informação serve como estímulo e exerce uma função primordial na promoção do diálogo, objetivando indicar e orientar os possíveis caminhos para o desenvolvimento de competências. Nesse processo, ocorre a perspectiva de que a mediação, através dos serviços de informação, busca incentivar formas de aprendizado, domínio, construção do conhecimento, tomadas de decisão em situações específicas/imediatas e gerais/mediatas, ou seja, a formação de competências informacionais, preparando os usuários para se tornarem autônomos (FARIAS, 2016).

Isto posto, pode-se estabelecer um encadeamento conceitual. A princípio, têm-se a prática do estudo de usuários, a fim de mapear as necessidades informacionais dos sujeitos da informação, com intuito de ofertar serviços e produtos pari passu com suas demandas emergentes. Posteriormente, designa a mediação no viés da satisfação de necessidades de informação, viabilizada a partir do estudo supracitado, condição sine qua non para propiciar a autonomia do usuário na escolha das fontes informacionais. Por fim, pode-se constatar a mediação da informação como campo que fomenta a formação de competências através de ações pedagógicas que oportunizem abordagens bilaterais nas formas de fortalecer a autônima do usuário na construção do conhecimento e tomadas de decisões.

À vista disso, em consonância com o cenário exposto, a mediação tem se revelado como ação orientadora de novas perspectivas para grupos de realidades diversas, sobretudo aos poucos assistidos. Dessa forma, percebe-se que a Biblioteconomia 
continua sem ocupar o espaço que lhe cabe, não apenas como ramo do conhecimento que se dedica a reunir, organizar, disseminar e produzir o conhecimento registrado, mas, essencialmente, como serviço social de relevância para a evolução dos grupos humanos e sociais (TARGINO, 2018).

\section{PERCURSO METODOLÓGICO}

A metodologia mostra-se um aspecto primordial para a construção de toda investigação científica. Diante disso, na finalidade da pesquisa, optou-se pela pesquisa exploratória, uma vez que, fundamentado em Ponte et al. (2007), esse método está diretamente relacionado ao aprimoramento ou descobertas de ideias para facilitar a construção de hipóteses sobre o tema, bem como tornar o problema mais compreensível. Isto posto, apresentou-se no referencial teórico essa nova perspectiva de atuação bibliotecária e as relações potenciais com a mediação da informação, considerando a multiplicidade e necessidades dos usuários.

$\mathrm{Na}$ estratégia de pesquisa, tem-se o estudo de caso com caráter exploratório. Dialogando com Prodanov e Freitas (2013), essa categoria de investigação, trata-se de um sujeito, de um grupo de pessoas, de uma comunidade etc. E, para sua efetivação com sucesso, são necessários alguns requisitos básicos, entre os quais se salientam: a severidade, objetivação, originalidade e coerência.

Quando à caracterização do objeto de pesquisa, o projeto Leitura\&Ação emerge da seleção de ações de extensão para a modalidade Protagonismo Estudantil (PROPE), viabilizado pela Pró-Reitoria de Extensão da Universidade Federal do Cariri (PROEX/UFCA). O Leitura\&Ação fora idealizado por discentes do curso de Biblioteconomia da UFCA e justifica-se pela carência no incentivo à leitura nos ambientes informacionais públicos de Juazeiro do Norte - Ceará. Os encontros ocorreram mensalmente e, para a execução das ações, ofertou-se: leituras dinâmicas em grupo, pinturas e desenhos, performances com as crianças, enfatizando a temática abordada, entre outras práticas mediacionais.

No que concerne ao lócus da pesquisa, a Comunidade Beneficente Zaíla Lavor, situa-se no bairro João Cabral, na cidade de Juazeiro do Norte - CE. Atualmente, a 
associação beneficia centenas de famílias que vivenciam, cotidianamente, situações de pobreza, exclusão e vulnerabilidade social, destacando uma atenção especial ao desenvolvimento de crianças e adolescentes, visando contribuir para a superação e resolução desses problemas.

Este centro comunitário desenvolve programas e projetos com o intuito de capacitar e empoderar crianças, jovens e famílias. Para isso, atua dentro de quatro enfoques programáticos: Pró-cidadania (7 a 14 anos); Treinarte (15 a 18 anos); Programa Educacional de Atenção a Famílias (PEAF); e Programa Reconexão Ancestral Integrada Por Zona de Ensino e Saberes (7 a 17 anos). O eixo de atuação escolhido para aplicação do Leitura\&Ação foi o Pró-cidadania, objetivando, através das práticas mediacionais, sensibilizar, difundir e favorecer a leitura, a fim de ampliar o repertório cultural das crianças e adolescentes.

No instrumento de coleta, optou-se pela observação participante como técnica de investigação, dado que, nesta abordagem, o pesquisador-observador se posiciona ao nível dos outros sujeitos que compõem o fenômeno do objeto a ser observado. Mediante tal particularidade, infere-se que o observador participante tem mais condições de compreender os hábitos, atitudes, interesses, relações humanas e características da vida diária da comunidade (RICHARDSON et al., 2011).

Após a coleta dos dados, com o intuito de estruturá-los, compará-los e representá-los sinteticamente, aplicou-se a análise de conteúdo com base no processo de codificação que, na concepção de Bardin (2009), corresponde a uma transformação dos dados brutos do texto até atingir uma representação do conteúdo. À vista disso, os dados foram analisados com base em três fases: a) pré-análise: exploração do material ou de leituras flutuantes do corpus do instrumento de coleta, de acordo com os objetivos da pesquisa; b) exploração do material: seleção das unidades de análise através do processo de categorização e subcategorização e, por fim, c) tratamento dos resultados obtidos e interpretação, que consiste na análise qualitativa do conteúdo a partir de categorias, o qual permite que o pesquisador compreenda as nuances de sentidos que existem entre os elementos. As categorias selecionadas foram: a) Educação e cidadania; e b) Ação cultural. 
Quadro 2 - Categorias da análise de conteúdo

\begin{tabular}{|c|c|c|}
\hline Categorias & Definições & Ações extensionistas \\
\hline \multirow[b]{2}{*}{$\begin{array}{l}\text { Educação e } \\
\text { cidadania }\end{array}$} & \multirow{2}{*}{$\begin{array}{l}\text { Ação informacional e educacional constituída a } \\
\text { partir do cotidiano das comunidades, visando a } \\
\text { satisfação de necessidades do dia-a-dia acerca } \\
\text { das múltiplas questões da realidade social. }\end{array}$} & Benefícios da leitura \\
\hline & & Educando com cordel \\
\hline \multirow[b]{2}{*}{ Ação cultural } & \multirow{2}{*}{$\begin{array}{l}\text { Conjunto de desenvolvimento de técnicas e } \\
\text { conhecimentos para condução e gestão das } \\
\text { práticas culturais e pedagógicas no âmbito da } \\
\text { realização de eventos, estímulo à inclusão } \\
\text { digital, exposições, ações lúdicas e outras } \\
\text { atividades de interesse da comunidade. }\end{array}$} & $\begin{array}{l}\text { A arte de pintar: brincando } \\
\text { com os desenhos }\end{array}$ \\
\hline & & $\begin{array}{c}\text { Conhecendo o Museu Bispo do } \\
\text { Rosário }\end{array}$ \\
\hline
\end{tabular}

Fonte: Elaborado pela autora com base em Silva (2017).

Mediante as etapas da análise de conteúdo, a definição das categorias expostas se deu com base do aparato teórico-conceitual sobre as perspectivas de atuação bibliotecária através das ações desenvolvidas pelo projeto Leitura\&Ação durante o ano de 2018, na Comunidade Beneficente Zaíla Lavor. Diante disso, essas categorias foram prédefinidas para a análise do material coletado, por meio de uma estrutura sintática dos conteúdos abordados nas ações.

\section{ANÁlISE DAS PRÁtICAS MEDIACIONAIS DO PROJETO LEITURA\&AÇÃO DESENVOLVIDAS NA COMUNIDADE BENEFICENTE ZAÍLA LAVOR}

Esta seção apresentará uma análise das ações veiculadas pelo projeto Leitura\&Ação com o objetivo de retratar, de forma mais fiel possível, os resultados obtidos após a coleta dos dados durante as práticas mediacionais desenvolvidas na Comunidade Beneficente Zaíla Lavor.

\subsection{EDUCAÇÃO E CIDADANIA}

Mediante o que pressupõe o Quadro 2, em relação à possibilidade de atuação em Centros Comunitários, como sendo ações informacionais constituídas a partir do cotidiano das comunidades e das múltiplas questões que envolvem essa realidade social, constata-se, para análise nessa categoria, duas ações: Benefícios da leitura e Educando com cordel. 


\subsubsection{Benefícios da leitura}

Nessa ação, foi exibido um vídeo educativo intitulado $A$ menina que odiava livros, dirigido por Jo Micuris, baseado no livro A menina que detestava livros, da escritora indiana Manjusha Pawagi. A história tem como personagem principal Nina, uma menina que não gostava de ler, contudo, ao se deparar com o rico universo da literatura, descobre uma nova realidade, uma nova paixão: a leitura.

Ao final do vídeo, abriu-se espaço para diálogo entre as crianças e os mediadores, com vistas a captar o feedback e conduzir os interlocutores a explanarem os traços marcantes do texto, que sucedeu em uma discussão produtiva sobre o hábito de ler. Outros aspectos levantados, referem-se à importância da leitura para a construção do ser sociocultural e a possibilidade de conhecer diversas culturas, crenças e tradições por intermédio da literatura.

O intuito dessa prática mediacional foi propor uma mediação para leitura, ao remeter a mediação como processo de responsabilidade educativa (SILVA; SILVA, 2012), com a preocupação pedagógica de instigar as crianças a ler e escrever, para que estas adquiram informações de que precisam de maneira independente, formando indivíduos conscientes e informados com a capacidade de modificar sua própria realidade.

Dando seguimento às atividades, aplicou-se a dinâmica Qual é a história?, com base nas histórias clássicas da literatura infantil como: Três porquinhos, $O$ pequeno príncipe, Chapeuzinho vermelho, Peter Pan, dentre outras narrações infantis. Essa atividade teve por finalidade relembrar as histórias narradas na infância por intermédio de mímicas. Isto posto, dividiu-se o grupo em dois para encenar os trechos fictícios da história e interpretá-los diante dos colegas.

Nota-se, após o delineamento dessas práticas, que a mediação para a leitura, a partir do ambiente de informação em questão, a Comunidade Beneficente Zaíla Lavor, deve ter como princípio norteador: estimular o usuário a interpretar o seu cotidiano, as suas condições e perspectivas de vida, tendo em vista que uma leitura distante da realidade cotidiana pode se configurar como algo inibidor da construção de sentidos (SILVA; FARIAS, 2018). 


\subsubsection{Educando com cordel}

A ação extensionista Educando com cordel denotou a dimensão da Literatura de Cordel como instrumento pedagógico que estimula a leitura e facilita a escrita. Essa ação foi desenvolvida na 9a Colônia de férias da Comunidade Beneficente Zaíla Lavor, abordando a temática Estatuto da Criança e do Adolescente (ECA). O encontro visou conscientizar as crianças em relação aos seus direitos e deveres perante a sociedade, através de atividades artísticas, culturais e esportivas.

Tais concepções justificam a inclusão dessa prática na categoria de Educação e Cidadania, em razão do processo mediacional ocorrer no âmbito dos serviços de informação utilitária relativos ao cotidiano das crianças. Com o intuito de alcançar essa perspectiva, para casar o objetivo da ação com o tema da colônia de férias, as atividades planejadas visaram concatenar o recorte histórico-conceitual da Literatura de Cordel em consonância aos elementos que a compõe, a fim de disseminar para as crianças sua relevância e aplicabilidade a temas diversos, em foco, a temática central do evento: o ECA.

Para iniciar as atividades, os mediadores explanaram sobre o conceito da Literatura de Cordel, embasados nas seguintes pontuações: a) a origem do cordel; b) sua disseminação através da propagação oral; c) as contribuições dos repentistas na sua disseminação; e d) o cordel na atual sociedade contemporânea. Durante o diálogo, pôdese constatar o interesse das crianças pela temática, todavia, nem todos conheciam essa assertiva, o que reflete na necessidade de inserir esse método de ensino nas salas de aula, para tornar o estudo mais prazeroso e dinâmico, valorizando também a cultura regional nordestina.

Após exposição das concepções históricas da Literatura de Cordel, disseminou-se os elementos básicos para a sua constituição (métricas, versos, estrofes e rimas) e dicas para produção, desde a escolha do tema até o ponto central da obra (narrativo, dissertativo, descritivo etc.). Com a discussão sobre a estrutura do cordel pretendeu-se disseminar para as crianças que, apesar da linguagem informal, acessível e de fácil compreensão, essa fonte de informação também possui embasamentos teóricos.

Seguidamente, houve a exibição dos vídeos $O$ cordel mais nojento do mundo e 
Marmelo, o jacaré banguelo, produzidos e declamados pela poeta pernambucana Mariane Bigio. Dessarte, a exposição dessas obras visuais, além de tornar o momento mais dinâmico e interativo, teve como primazia mostrar para as crianças que a produção de cordéis constitui uma gama de temáticas, como: reflexões do cotidiano, problemas sociais, humor, aspectos técnicos como a musicalidade, dentre outros.

Neste contexto, compreende-se que as atividades viabilizadas no primeiro momento condizem com as percepções explanadas por Marteleto (2009), quando a autora afirma o caráter conceitual da mediação a partir de uma construção teórica destinada a refletir sobre as práticas e os dispositivos que compõem os arranjos de sentidos. Fazendo uma analogia dessa citação com a prática mediacional aqui delineada, no que concerne à contextualização da Literatura de Cordel explicitada sob uma perspectiva lúdica para as crianças, pode-se refletir as formas informacionais de se apresentar os elementos que compõem os gêneros literários, em questão o cordel, no sentido de propiciar a prática da leitura e da escrita.

Assim, infere-se que as práticas de mediação informacional utilizadas nessa atividade estão concatenadas com a mediação da leitura explícita dado que, em consonância com Silva e Farias (2018), pôde incitar o letramento informacional e, consequentemente, o estímulo à pesquisa sobre essa manifestação literária da cultura popular brasileira típica da região Nordeste. Além disso, exerceu uma função primordial na formação de competências, à medida que indicou, orientou e despertou possíveis caminhos para o desenvolvimento de futuros poetas.

No segundo momento, mediou-se um diálogo sobre o ECA, esclarecendo às crianças e adolescentes algumas informações utilitárias quanto à efetivação dos seus direitos referentes à vida, à saúde, à alimentação, à profissionalização, à dignidade, entre outras pontuações, como dispõe o Art. 4ำ da Lei nํ 8.069/1990, dando destaque ao quarto capítulo que discorre acerca do direito à educação, à cultura, ao esporte e ao lazer, focalizado na atuação do eixo pró-cidadania da comunidade em questão.

Para finalizar, após explanações supracitadas, as crianças foram convidadas a escrever poesias em grupo, com no mínimo uma estrofe (4 a 5 linhas), abordando como temática o ECA e as atividades realizadas durante a 9a Colônia de férias da Comunidade Beneficente Zaíla Lavor. No ato da escrita, observou-se a dificuldade das crianças em 
colocar suas ideias no papel, além do conflito de trabalhar e pensar coletivamente enquanto grupo, por isso a necessidade de se trabalhar tal temática.

O objetivo da ação Educando com cordel visou fomentar a prática da leitura e a formação da linguagem escrita para os participantes, com ênfase na aplicação da metodologia interacionista de Vygotsky (1984). Neste caso, o autor preconiza que essa atividade humana pressupõe o uso de instrumentos psicológicos explícitos, em questão, a linguagem de fala e escrita como sistemas de signos, os quais assumem um caráter mediador nas relações desenvolvidas por cada indivíduo, refletindo diretamente no impacto das intervenções pedagógicas e na reconstrução do saber e no desenvolvimento da subjetividade do educando por intermédio da interação social.

\subsection{AÇÃO CULTURAL}

Mediante o que pressupõe o Quadro 2, sobre a categoria Ação Cultural, como sendo um conjunto de desenvolvimento de técnicas e conhecimentos para condução de práticas culturais e pedagógicas no âmbito de atividades de interesse da comunidade, constata-se, para análise nessa categoria, dentre as práticas mediacionais viabilizadas pelo projeto Leitura\&Ação, duas ações: $A$ arte de pintar e Conhecendo o Museu do Bispo do Rosário.

\subsubsection{A arte de pintar: brincando com os desenhos}

Infere-se que a proposta pensada para essa ação está inclusa na categoria de Ação Cultural, devido referir-se a uma contribuição educativa na realidade social da criança ao retratar a mediação da informação direcionada ao estímulo da cultura, como assegura o referencial teórico. Neste sentido, a temática aludida nessa prática mediacional teve como escopo o Dia do Pintor Plástico (8 de maio), com o propósito de ampliar a compreensão da produção cultural e o acesso aos bens culturais universais, no sentido de facultar a formação cultural dos participantes e a criação de novos conhecimentos por meio da arte de pintar.

O início das atividades se deu com o relato de trechos da história do pintor e 
desenhista brasileiro José Ferraz de Almeida Júnior, o primeiro a retratar o tema regionalismo nas artes plásticas do século XIX, com o quadro Pinacoteca do Estado de São Paulo (1892). Seguidamente, apresentou-se a história do pintor brasileiro Cândido Portinari com o auxílio de um vídeo educativo do Quintal da Cultura, no qual os apresentadores contam a história do pintor baseado em algumas de suas telas.

Com tal característica, foram exibidos para as crianças obras como: Natália com palhacinhos (19--); Meninos brincando (1955); Circo (1932); Roda infantil (1932) e Futebol (1935), retratando que toda a infância de Portinari era repleta de brincadeiras e muita arte. Ele procurou mostrar em suas pinturas tudo o que via, desenhando suas memórias de infância para registrar e resgatar as brincadeiras e jogos da sua época como: empinar papagaio, rodar pião, jogar bola, plantar bananeira, pular carniça etc.

Essa viagem pelos registros da memória de Portinari suscitou desenvolver uma sensibilidade artística e um senso crítico nas crianças a partir da cultura e da arte, características essenciais para a formação cognitiva do sujeito. Outrossim, com a aplicabilidade dessa prática, percebeu-se a importância de registrar as nossas memórias, seja por pintura, escrita, fotografia, entre outros objetos de representação. Essa prática propicia o enfoque de recordações e, também, é capaz de partilhar e disseminar as informações históricas para futuras gerações.

Após mediação das obras, finalizou-se com a Hora da pintura, ocasião em que o público registrou a primeira lembrança da sua vida, a mais recuada impressão que guardou, bem como os objetos marcantes da sua infância. Essa atividade oportunizou aos participantes trabalharem a coordenação motora, identificar e explorar as cores, desenvolver a imaginação, criatividade, atenção, expressão artística, entre outras competências. Os materiais utilizados para engrandecer as obras foram: lápis de cor, papel ofício, cola para papel, glitter, feijão, arroz, flores naturais, lápis e caneta.

A execução dessa atividade se releva, em concordância com Vygotsky (1984), porque o desenho deve ser interpretado como um estágio preliminar do desenvolvimento da escrita, tendo ambos as mesmas origens de construção: a linguagem falada, isto é, o desenho é um instrumento que as crianças se utilizam ludicamente para interagir com o mundo à sua volta e compreendê-lo, causando, assim, um impacto em sua formação psíquica. 
Deste modo, as práticas de ação cultural buscaram alicerces na mediação explícita de cunho pedagógico sociocognitivo, pensando o usuário a partir de uma autonomia no processo de construção de sentido ao apropriar-se da informação cultural (SILVA, 2012). Logo, compreende-se que a mediação de estímulo à cultura cria estratégias de ampliar as possibilidades de acesso à informação, tornando o ambiente informacional mais democrático, plural e acessível.

\subsubsection{Conhecendo o Museu Bispo do Rosário}

Com o diagnóstico realizado na Comunidade Beneficente Zaíla Lavor, deparou-se com a necessidade de pensar em práticas mediacionais que integrassem as crianças do Pró-cidadania em ambientes informacionais nos quais acontecessem processos de educação não formais. Isto posto, optou-se por abordar, nessa ação cultural, os materiais e jogos educativos sobre o Museu do Bispo do Rosário Arte Contemporânea, obra-tema da Caixa dos Escolhidos, idealizada pelas designers Lygia Santiago e Amanda Lianza, em parceria com o Serviço Social do Comércio (SESC).

O intuito dessa proposta foi possibilitar as dimensões distintas da experiência humana e cultural, para a construção do processo criativo por meio do contato com objetos e imagens museológicas. A princípio, iniciou-se um diálogo sobre a existência dos museus, sua funcionalidade, tipologias e o acervo de que estes espaços culturais dispõem. Dentre os museus, destacaram o Memorial Padre Cícero, o Museu Paroquial e a Casa Museu do Pe. Cícero, localizados em Juazeiro do Norte - CE. Além disso, foi questionado se as crianças tinham participado de alguma visita técnica a esses locais através das suas escolas, todavia, houve uma unanimidade nas respostas, todos afirmaram que as escolas não oferecem esse tipo de atividade.

Com isso, exibiu-se o vídeo educativo Por que existem os museus?, da série Narrativas do Brasil, idealizada pelo canal infantil Ticolicos do Ministério da Cultura. Nesse vídeo, o fantoche Ludi apresenta relatos de crianças que já visitaram um museu ou exposição de arte, expondo suas percepções sobre as tipologias dos museus e o acervo disponibilizado, bem como sua a função primordial em resguardar uma determinada história (ex.: dinossauros, futebol, história de um país etc.). 
Após essas considerações iniciais, os mediadores expuseram a história do artista nordestino Arthur Bispo do Rosário (1909-1989), o qual tinha como característica intrínseca produzir suas obras com objetos do lixo e da sucata. Por conseguinte, utilizouse a caixa pedagógica mencionada, contendo três diferentes jogos educativos ${ }^{1}$ : um jogo de tabuleiro, um dominó e um quebra-cabeças. O uso desses instrumentos pedagógicos facilitou a compreensão da temática proposta, instigando nas crianças o conhecimento sensível e intelectual a partir das novas experiências culturais.

Por fim, entende-se que a prática mediacional teve um caráter explícito e pedagógico, visto que buscou contribuir para a ampliação do repertório estético e cultural, cooperando na formação de crianças e adolescentes em ambientes informais da educação. Neste sentido, por meio dessa prática, os sujeitos se integram e compartilham seus saberes e percepções. Similarmente, embasados por Silva (2015), objetivou-se contribuir para a apropriação e aprendizagem do educando por meio das interações e internalizações educativas estratégicas, com o intuito de modificar as operações psicológicas, históricas, culturais, sociais do ser.

\section{CONSIDERAÇÕES FINAIS}

Dentre essas contribuições que o projeto Leitura\&Ação proporcionou para a Comunidade Beneficente Zaíla Lavor, no âmbito da informação, pode-se mencionar os processos de serviços utilitários, estudo de usuários e ação cultural, que fortaleceram as praxes do projeto, beneficiando os sujeitos envolvidos nessa comunidade. No contexto da cultura, as práticas mediacionais, contribuíram para o estabelecimento de uma rede cultural, pelo caráter coletivo, dialógico e interacionista, através de reflexões relacionadas a valores, crenças, racionalidade, normas, dentre outras particularidades que cooperam na formação do grupo Pró-Cidadania. Em relação a esfera da educação, as práticas mediacionais evidenciaram contextos em que esse centro comunitário poderá adotar novas metodologias educacionais ativas para a construção de espaços de diálogo, além de fomentar a busca pela educação continuada do quadro de colaboradores que o

\footnotetext{
${ }^{1}$ A elaboração dos materiais teve como referência as obras do artista: o tabuleiro foi bordado à mão e depois digitalizado. Os dominós possuem imagens de obras que podem ser lidas pela quantidade, e a imagem aquarelada do quebra-cabeças é uma cópia da obra o Grande Veleiro.
} 
compõe.

No tocante à identificação dos elementos que norteiam práticas mediacionais ofertadas pelo projeto Leitura\&Ação na Comunidade Beneficente Zaíla Lavor elencado, pode-se constatar: mediação de leitura, mediação como estímulo a cultura, mediação pedagógica e estudo de usuários como os principais aspectos evidenciados nas atividades do projeto. Levando em consideração o respaldo epistemológico desses elementos para nortear suas intervenções em sentido pragmático, destaca-se a dinamização nos serviços informacionais, assim como suas respectivas contribuições particularizadas e coletivas.

Vale destacar, os impactos mediacionais no que tange às práticas do projeto Leitura\&Ação na Comunidade Beneficente Zaíla Lavor, como: a) mediação de leitura: fomento ao gosto pela leitura para com as crianças e interpretar suas vivências do cotidiano; desenvolvimento do repertório pessoal dos educandos, no ato da leitura e o enriquecimento das habilidades linguísticas, como a fala, escuta e escrita; b) estímulo a cultura: no alcance ao letramento informacional e formação de valores, crenças e processos éticos, assim como na expansão de vocabulário, criatividade; c) mediação pedagógica: promovendo a autonomia para a construção de sentidos e apropriação da informação cultural, visando à preparação aos estudos escolares.

Mediante essas explanações, constata-se que, dentre as contribuições do projeto Leitura\&Ação via práticas mediacionais, além de reforçar as atividades já desenvolvidas pela Comunidade Beneficente Zaíla Lavor, o projeto também colaborou no fortalecimento dos princípios dessa organização social, das capacidades e qualificações dos interventores. O projeto possibilitou novas perspectivas de atuação bibliotecária conforme os serviços informacionais desenvolvidos, tendo a mediação da informação como respaldo para galvanizar práticas formativas pelo teor interdisciplinar.

Em linhas gerais, a presente pesquisa tenciona que novos estudos sejam gerados nesse sentido, alicerçados em outras áreas do conhecimento desenvolvidas em centros comunitários, sob o ponto de vista de ambientes potenciais que podem contribuir para a formação cidadã dos grupos menos favorecidos. Por fim, de acordo com as práticas mediacionais do projeto Leitura\&Ação, outras temáticas de teor social ou científico possam ser desempenhadas nesses espaços, pesquisas científicas e atuação profissional pelo viés educativo, formativo, científico, cultural e tecnológico. 


\section{REFERÊNCIAS}

ALMEIDA, Marco Antônio de.; DAMIAN, leda Pelógia Martins. Humanidades digitais: um campo praxiológico para mediações e políticas culturais. In: ENCONTRO NACIONAL DE PESQUISA EM CIÊNCIA DA INFORMAÇÃO, 16., 2008, São Paulo. Anais eletrônicos [...] João Pessoa: UFPB, 2015. Disponível em:

http://repositorios.questoesemrede.uff.br/repositorios/bitstream/handle/123456789/28 38/16.\%20HUMANIDADES\%20DIGITAIS.pdf?sequence=1. Acesso em: 20 jul. 2020.

ALMEIDA JÚNIOR, Oswaldo Francisco de. Mediação da informação: dimensões. OFAJ, [s. I.], nov. 2015. Disponível em: https://www.ofaj.com.br/colunas_conteudo.php?cod=939. Acesso em: 11 jul. 2020.

ALMEIDA JÚNIOR, Oswaldo Francisco de. Mediação da informação e múltiplas linguagens. In: ENCONTRO NACIONAL DE PESQUISA EM CIÊNCIA DA INFORMAÇÃO, 9., 2008, São Paulo. Anais eletrônicos [...] São Paulo: USP, 2008. Disponível em: http://repositorios.questoesemrede.uff.br/repositorios/bitstream/handle/123456789/13 43/Media\%20informação.pdf?sequence=1. Acesso em: 20 jul. 2020.

BARDIN, Laurence. Análise de conteúdo. Lisboa: Edições 70, 2009.

BRASIL. Lei no 8.069, de 13 de julho de 1990. Dispõe sobre o Estatuto da Criança e do Adolescente e dá outras providências. Brasília. Disponível em: http://www.planalto.gov.br/ccivil_03/LEIS/L8069.htm. Acesso em: 4 dez. 2020.

COUZINET, Viviane. Complexidade e documento: a hibridação das mediações nas áreas em ruptura. RECII - R. Eletr. de Com. Inf. Inov. Saúde, Rio de Janeiro, v. 3, n. 3, p. 10-16, set., 2009.

DUARTE, Adriana Bogliolo Sirihal. Mediação, usos e usuários: reflexões e análise de caso. In: ENCONTRO NACIONAL DE PESQUISA EM CIÊNCIA DA INFORMAÇÃO, 12., 2011, Brasília. Anais [...] Brasília: UNB, 2011.

FARIAS, Maria Giovanna Guedes. Mediação e competência em informação: proposições para a construção de um perfil de bibliotecário protagonista. InCID: R. Ci. Inf. e Doc., Ribeirão Preto, v. 6, n. 2, p. 106-125, set. 2015/fev. 2016. Disponível em: https://www.revistas.usp.br/incid/article/view/101368. Acesso em: 3 jan. 2021.

GOMES, Henriette Ferreira. A dimensão dialógica, estética, formativa e ética da mediação da informação. Informação \& Informação, Londrina, v. 19, n. 2, p. 46-59, 2014. Disponível em: http://www.uel.br/revistas/uel/index.php/informacao/article/view/19994. Acesso em: 3 jan. 2020

GOMES, Henriette Ferreira. A mediação da informação, comunicação e educação na construção do conhecimento. DataGramaZero, João Pessoa, v. 9, n. 1, fev., 2008. Disponível em: https://brapci.inf.br/index.php/res/download/45248. Acesso em: 5 jan. 
2021.

MARTINS, Alessandra Negrão Elias et al. Atendimento em mediação familiar com ou para idosos. Portal do Envelhecimento, [s. I.], 9 jun. 2014. Disponível em:

http://www.portaldoenvelhecimento.com/violencia/item/3223-atendimento- emmediação-familiar-com-ou-para-idosos. Acesso em: 8 jun. 2020.

MARTELETO, Regina Maria. Jovens, violência e saúde: construção de informações nos processos de mediação e apropriação de conhecimentos. RECIIS: R. Eletr. de Com. Inf. Inov. Saúde, Rio de Janeiro, v.3, n.3, p. 17-24, set., 2009. Disponível em:

https://www.reciis.icict.fiocruz.br/index.php/reciis/article/view/751. Acesso em: 30 dez. 2020.

PONTE, Vera Maria Rodrigues et al. Análise das metodologias e técnicas de pesquisa adotados nos estudos brasileiros sobre balanced scrorecard: um estudo dos artigos publicados no período de 1999 a 2006. In: AnpCONT, 1., 2007, Gramado. Anais [...] Gramado, 2007.

PRODANOV, Cleber Cristiano; FREITAS, Ernani Cesar de. Metodologia do trabalho científico [recurso eletrônico]: métodos e técnicas da pesquisa e do trabalho acadêmico. 2. ed. Novo Hamburgo: Feevale, 2013. Disponível em:

https://www.feevale.br/institucional/editora-feevale/metodologia-do-trabalho-cientifico--2-edicao. Acesso em: 28 dez. 2020.

RICHARDSON, Roberto Jarry et al. Pesquisa social: métodos e técnicas. 3 ed. São Paulo: Atlas, 2011.

SILVA, Antonio Zaquiel Barbosa da. As relações de mediação, aprendizagem e desenvolvimento humano: um diálogo entre Vigotski e Paulo Freire. 2012. 134 f. Dissertação (Mestrado Interdisciplinar) - Programa de Pós-graduação Cultura e Sociedade, Universidade Federal do Maranhão, São Luís, 2012.

SILVA, Armando Malheiro da. Mediações e mediadores em Ciência da Informação.

Prisma.com, Porto, n. 9, p. 1-37, 2010. Disponível em:

http://ojs.letras.up.pt/index.php/prismacom/article/view/2057/0. Acesso em: 5 jan. 2020.

SILVA, Jonathas Luiz Carvalho. Como atuar em bibliotecas comunitárias? OFAJ, [s. I.], jun. 2017. Disponível em: https://www.ofaj.com.br/colunas_conteudo.php?cod=1060. Acesso em: 4 jun. 2020.

SILVA, Jonathas Luiz Carvalho. Necessidades de informação e satisfação do usuário: algumas considerações no âmbito dos usuários da informação. InCID: R. Ci. Inf. e Doc., Ribeirão Preto, v. 3, n. 2, p. 102-123, jul./dez. 2012. Disponível em:

http://www.revistas.usp.br/incid/article/view/48656/52727. Acesso em: 7 ago. 2020.

SILVA, Jonathas Luiz Carvalho. Percepções conceituais sobre mediação da informação. 
InCID: R. Ci. Inf. e Doc., Ribeirão Preto, v. 6, n. 1, p. 93-108, mar./ago. 2015. Disponível em: https://www.revistas.usp.br/incid/article/view/89731. Acesso em: 15 out. 2020.

SILVA, Jonathas Luiz Carvalho; FARIAS, Maria Giovanna Guedes. Abordagens conceituais e aplicativas da mediação nos serviços de informação. InCID: R. Ci. Inf. e Doc., Ribeirão Preto, v. 8, n. 2, p. 106-123, set. 2017/fev. 2018. Disponível em: https://www.revistas.usp.br/incid/article/view/122628. Acesso em: 18 out. 2020.

SILVA, Jonathas Luiz Carvalho; SILVA, Andreia Santos Ribeiro. A mediação da informação como prática pedagógica no contexto da biblioteca escolar: algumas considerações. Biblioteca Escolar em Revista, Ribeirão Preto, v. 1, n. 2, p. 1-30, 2012. Disponível em: https://www.revistas.usp.br/berev/article/view/106561. Acesso em: 05 jan. 2021.

TARGINO, Maria das Graças. Transformando bibliotecas, transformando sociedades: reflexão sobre o papel dos bibliotecários à luz das demandas sociais. OFAJ, [s. I.], mar. 2018. Disponível em: https://www.ofaj.com.br/colunas_conteudo.php?cod=1118. Acesso em: 22 nov. 2018.

VARELA, Aida. Informação, cognição e mediação: vertentes, contextos e pretextos. RICI, Rio de Janeiro, v. 1, n. 1, p. 21-45, jan./jun., 2008. Disponível em:

https://brapci.inf.br/index.php/res/download/86833. Acesso em: 05 jan. 2021.

VYGOTSKY, Lev. A formação social da mente. São Paulo: Martins Fontes, 1984.

\section{Declaração de Contribuição dos Autores}

Arysa Cabral Barros - Conceptualização - Curadoria dos Dados - Análise Formal Aquisição de Financiamento - Investigação - Metodologia - Administração do Projeto Recursos - Software - Visualização - Escrita (rascunho original) - Escrita (análise e edição).

Jonathas Luís Carvalho Silva - Conceptualização - Investigação - Metodologia Supervisão - Validação - Escrita (análise e edição). 